\title{
Periodontal disease in a Portuguese identified skeletal sample from the late nineteenth and early twentieth centuries
}

\begin{tabular}{|c|c|}
\hline Journal: & American Journal of Physical Anthropology \\
\hline Manuscript ID: & AJPA-2010-00044.R2 \\
\hline Wiley - Manuscript type: & Research Article \\
\hline $\begin{array}{r}\text { Date Submitted by the } \\
\text { Author: }\end{array}$ & $\mathrm{n} / \mathrm{a}$ \\
\hline Complete List of Authors: & $\begin{array}{l}\text { Wasterlain, Sofia; University of Coimbra, Department of Life } \\
\text { Sciences } \\
\text { Cunha, Eugénia; University of Coimbra, Department of Life } \\
\text { Sciences } \\
\text { Hillson, Simon; University College London, Archaeology }\end{array}$ \\
\hline Key Words: & paleopathology, periodontitis, epidemiology, Coimbra \\
\hline
\end{tabular}

\section{SCHOLARONE Manuscripts}




\begin{abstract}
Periodontal status was investigated in 600 adult dentitions belonging to the identified osteological collections curated at the University of Coimbra, Portugal. These collections date to a point temporally intermediate between the large epidemiological studies of the $20^{\text {th }}$ century and archaeological collections that antedate the $19^{\text {th }}$ century. The aim of this study is to compare periodontal data derived from contemporary samples with statistics compiled from epidemiological studies to determine if factors such as age-at-death, sex and tooth type are essential or not to account for in future archaeological studies of periodontitis. Periodontal disease status was assessed based on the textural and architectural variations of the interdental septum and the extent of bone loss. Overall, the frequency of periodontitis within the Coimbra collections is $73.8 \%$. Men were more susceptible to periodontal disease than women.

Gingivitis was widespread in the younger age groups. Destructive periodontitis was observed early in adulthood, rising steadily with age. The most susceptible sites to periodontal breakdown were located in the posterior region of the upper jaw. Some variation in reported frequencies of periodontitis was found in epidemiological reports, which might result from variation in methods for identifying the pathology, differences in the age composition of the samples examined, variation in oral hygiene and/or diet, or some other factors. Regarding the pattern of distribution of periodontal disease, Coimbra results were similar to comparable modern epidemiological surveys, making clear the importance of considering sex, age and oral distribution of periodontitis in future archaeological studies.
\end{abstract}


Periodontal disease is an inflammatory condition that affects any or all portions of the periodontium, which includes the gingivae, periodontal ligament, alveolar bone and cementum (Lavigne and Molto, 1995). Traditionally, periodontal disease has been divided into two general categories based on whether attachment loss has occurred: gingivitis and periodontitis (Williams et al., 1992; American Academy of Periodontology, 2003). The term gingivitis is used to designate inflammatory lesions that are confined to the marginal gingivae, without loss of connective tissue attachment. Once the lesions extend to include destruction of the connective tissue attachment of the tooth and loss of alveolar bone the disease is designated periodontitis (Soames and Southam, 2005).

Periodontal disease has a multifactorial aetiology, but of prime importance is bacterial plaque, for without such plaque the disease will not occur. There is overwhelming evidence supporting this view, including epidemiological, pathological, microbiological, and immunobiological data (see Williams et al., 1992). In addition, a number of well recognized factors, namely calculus, diet, and oral hygiene, among others, may influence the nature and progression of periodontal disease.

The diagnosis of periodontal disease is difficult because no one feature is pathognomonic. Generally, gingivitis is diagnosed by the presence and extent of gingival inflammation, frequently measured as bleeding on probing (Page and Eke, 2007). The clinical recognition of periodontitis is made by periodontal probe measurements (i.e., probing depths, clinical attachment loss, etc.) and by radiographs, which document the pattern and extent of alveolar bone loss (Apsey et al., 2006; American Academy of Periodontology, 2003). The patient's age, medical and dental histories, as well as the presence or absence of miscellaneous signs and symptoms (including gingival recession, pain, ulceration, tooth mobility, previous treatment, occlusal problems, and amount of observable plaque and calculus) may help the 
clinician arrive at a diagnosis of periodontitis (American Academy of Periodontology, 2003; Page and Eke, 2007).

In dry bone specimens there is the difficulty of distinguishing the remodelling of the alveolar process related to tooth wear, occlusal forces, and continuous eruption from that due to periodontal disease. Even after initial eruption during childhood and young adulthood, the permanent teeth continue to erupt throughout adult life at a slow rate. Part of this is due to deposition of cement on the roots (hypercementosis), but a more important factor seems to be the remodelling of the bone in the jaws. The sockets gradually migrate upwards through the alveolar process, carrying the teeth with them. As a result, even where there is no bone loss due to periodontal disease, the roots of the teeth are progressively exposed with increasing age while the sockets become shallower. This is known as continuous eruption (Hillson, 2000, 2005). In some archaeological collections, it is therefore difficult to disentangle root exposure due to continuous eruption (and other remodelling of the alveolar process) from the active bone resorption that relates to periodontal disease. This is because there is no independent way of measuring the extent to which the alveolar process has been reduced in height (Hillson, 2005). Besides, where a large proportion of the alveolar process has been lost, it may be difficult to distinguish the defects of periapical inflammation (Hillson, 2000). It is therefore important to be able to differentiate between these processes and thereby avoid overestimating the frequency of periodontal disease among peoples of the past.

Epidemiological studies of living people have identified a strong pattern of susceptibility for different teeth and sites within the mouth (Ånerud et al., 1983; Baelum et al., 1988). These studies also identify sex differences in periodontitis prevalence, usually with higher periodontitis rates in men (Baelum et al., 1988), although some studies do not always distinguish between men and women. All studies, however, report a strong progression with age (Baelum et al., 1988). Despite these findings, archaeological studies frequently fail to 
consider factors such as age-at-death and sex when reporting periodontitis in past populations. In those studies where this has been attempted, men were found to be more affected than women (Costa, 1982) and a marked progression in periodontitis affectation that parallels indicators of increasing age-at-death was reported (Kerr, 1989, 1991, 1998b). If this is so then, where all age groups and both sexes are combined together, it is implicitly assumed that they have an equal chance of being recorded, in all assemblages studied. This is not the case for most archaeological collections, which often have fewer than expected female skeletons (see discussion in Waldron, 1994, $\mathrm{p}$ 23), perhaps due to a preference in burial, or to taphonomic factors. Furthermore, an examination of statistical tables in the United Nations Demographic Yearbooks (available online at http://unstats.un.org/unsd/demographic/products/dyb/dyb2.htm) shows that the sexes are never evenly distributed by age in death assemblages - there tend to be more girls than boys in the infant age group, fewer girls/women throughout most of child- and adulthood, and more women in the oldest age groups. Besides, most archaeological studies of periodontal disease have calculated periodontal disease rates from the total number of sites without distinguishing between different regions of the dentition. Those studies that have made this distinction (Clarke et al., 1986; Kerr, 1989, 1991, 1998a,b) report marked contrasts between different sites. If this is so then, where all sites are combined together, it is implicitly assumed that all sites throughout the jaw have an equal chance of being recorded, in all assemblages studied. This is not the case for most archaeological or museum collections. Periodontal disease particularly affects the molars, and it is quite often to find mandibles which anterior teeth are still present whereas the posterior teeth are not. This pattern strongly suggests that periodontal disease had a major part in the loss of the teeth but it must be kept in mind that dental caries is also common in populations with periodontal disease, and molars are particularly affected by it, so that teeth may have been extracted for this reason (Hillson, 2000). Besides, teeth may 
also be lost, in heavy wear rate groups, through the processes of fracturing and rapid continuous eruption. For all these reasons, the assumptions made in archaeological studies are likely to have a profound influence on periodontal disease rates.

In light of these issues, the aim of this study is to compare periodontal data derived from skeletal samples with statistics compiled from epidemiological studies to determine if factors such as age-at-death, sex and tooth type are essential or not to account for in future archaeological studies of periodontitis.

To test for this, it is necessary to isolate, as far as possible, the different factors. Such a test requires a collection of dentitions from a death assemblage that represents a well-defined group of people who lived under conditions that differ little from those of living people, particularly in not being subjected to the very rapid wear, which characterizes most archaeological collections that antedate the early years of the $19^{\text {th }}$ century. To be directly comparable to the demographic characteristics of a clinical study, ages-at-death and sex need to be known independently from the skeletal remains themselves. This is especially important for age-at-death since age is extremely difficult to estimate reliably in older adult skeletons. In addition, there should be a relatively even spread of age groups across the full range of adult life. Such collections are rare, but one exists in the Coimbra Identified Osteological Collections of the Museum of Anthropology at the University of Coimbra in Portugal. These collections encompass around 2,000 skulls and dentitions of people from Portugal, who were mostly of low socioeconomic status and who died during the late $19^{\text {th }}$ and early $20^{\text {th }}$ centuries (Cunha and Wasterlain, 2007). These individuals represent a well-defined group of people who lived under conditions that differed little from those experienced by people living today, particularly in not being subjected to the very rapid wear, which characterizes most archaeological collections that antedate the early years of the $19^{\text {th }}$ century. This places them at 
a point temporally intermediate between the large clinical studies of the $20^{\text {th }}$ century and archaeological collections that antedate the $19^{\text {th }}$ century.

Given that there is detailed and independent information about the individuals belonging to Coimbra collections, very specific questions can be posed:

1. Does the Coimbra collection display a pattern of susceptibility for periodontal disease among different teeth and sites within the mouth similar to that found by epidemiological studies among the living?

2. Is the Coimbra collection marked by a progression in periodontal disease prevalence similar to that found in modern clinical studies?

3. Does the Coimbra collection exhibit differences between males and females in the age-related progression of periodontal disease and do these vary between age groups in a fashion similar to that documented by epidemiological studies among living people?

\section{MATERIALS AND METHODS}

\section{The Coimbra Identified Osteological Collections}

The sample evaluated for this analysis comes from the Coimbra Identified Osteological Collections, curated by the Museum of Anthropology of the University of Coimbra (MAUC). There are three osteological collections at the MAUC that make up the Coimbra Identified Osteological Collections. These include the Medical School (MS, 585 skulls), the International Exchange (IE, 1075 skulls) and the Identified Skeletal (IS, 505 skeletons) collections. The skulls belonging to the Medical School collection were acquired from the Schools of Medicine in Lisbon and Porto and also from the Anatomical Theatre of the University of Coimbra, whereas skeletal material from both International Exchange and 
Identified Skeletal collections was recovered from the "Cemitério Municipal da Conchada" in Coimbra.

In Portuguese cemeteries it is common practice to perform exhumations after a period of five years. The bones are then required to be transferred for deposition in an ossuary. However, if relatives do not claim the remains following exhumation or cease payment of ossuary fees the remains are either placed in a communal grave or cremated. It was at that time that Coimbra University intervened and asked to house the remains for research purposes (Cunha and Wasterlain, 2007).

Individuals in the MS, IE and IS collections died between the years 1895-1903, 19041938 and 1904-1938, respectively. As these were fully identified individuals, detailed information about each, namely birthplace, sex and age at death, year and place of death, illness or cause of death, and occupation, amongst others, is compiled in a Record Book. These records make clear the low socioeconomic status of most individuals in the collections. According to these records, the women were almost exclusively engaged as housewives whereas men were employed mainly as rural workers and artisans. Furthermore, the provenance of their bodies can also be considered a sign of their low socioeconomic status, for in most cases their families could not afford adequate burials (Cunha and Wasterlain, 2007).

\section{The Sample}

Since previous studies (Kerr, 1989, 1998a,b; Oztunc et al., 2006) have suggested an increase in the frequency of periodontal disease in adults with advancing age, it was important to analyze individuals by age group. Therefore, 600 specimens were randomly selected in order to have six age groups (age group 1: 20-29 yrs; age group 2: 30-39 yrs; age group 3: 4049 yrs; age group 4: 50-59 yrs; age group 5: 60-69 yrs; and age group 6: 70-79 yrs) composed 
of 100 individuals, with 50 males and 50 females in each. Non-adults were deliberately excluded from the study due to insufficient number of children and juveniles in the collections. The selected individuals died in central Portugal between 1896 and 1938. Ideally it would be known if these individuals had life-long, or at least long-term, residence in the same geographic region, but this information was not available. It is known, however, that all of the selected individuals had been born and had died in the centre of Portugal.

The dental collection analyzed in this research $(9,562$ permanent teeth and 17,997 interdental septal areas) is one of the largest and best preserved anywhere. This is important because low numbers of individuals/septal areas could easily result in false high or low values for periodontitis statistics.

\section{Dental examination}

Initially, teeth were examined for presence, post-mortem absence, ante-mortem absence, partial eruption, anomalous eruption, or no eruption (as a result of young age, impaction or agenesis). The assessment of which teeth had been lost before death and which after death was done by considering the condition of the socket margins. It was assumed that a tooth had been lost post-mortem if there was an empty alveolus with no sign of remodelling. Ante-mortem tooth loss was assumed when there was at least a trace of remodelling in the socket or alveolar process. Third molars were only recorded as lost ante-mortem when they had left distinct traces of proximal wear on the distal surface of the adjacent second molar. All retained roots were recorded as remaining teeth. In all, 19,188 tooth positions and 9,562 permanent teeth were analyzed.

Occlusal attrition levels were recorded for each tooth using the Smith (1984) system while approximal attrition scores were registered according to Hillson (2001). In this paper the 
phrase "tooth type" is used to refer to a specific tooth in the dentition regardless of side (e.g., mandibular first molars) rather than to an entire class of tooth (e.g., molars).

\section{Recording periodontal disease}

Several methods have been used to assess the frequency of periodontal disease in past populations. Traditionally, periodontitis has been assessed only by measuring the distance between the cemento-enamel junction (CEJ) of the tooth and the crest of the alveolar bone (alveolar crest or AC is formed where the buccal and lingual plates come together with the alveolar bone at the tops of the sockets (Kingsmill, 1991; Lavigne and Molto, 1995). This linear measurement, however, overestimates the frequency of periodontitis because it ignores the continuous eruption of teeth (above). As a result, the only way to diagnose the modern human pattern of periodontal disease for certain is to find the crater-like loss of alveolar bone before further remodelling has taken place (Hillson, 2005).

In an attempt to isolate bone loss specifically due to periodontal disease, Kerr (1988) developed a scoring system based only on the interdental walls of the alveolar process (see Table 1). This method assesses two aspects of septal change, form and texture. A good histological correlation between the condition of crestal alveolar bone in modern clinically diagnosed periodontal disease situations and that of the textural and architectural variations of interproximal bone crest seen in archaeological skeletal material was demonstrated by Kerr (1988). According to Kerr's $(1989,1998$ a) interpretation, each score of his scheme is related to the progress of periodontal disease: Category 1 is considered to represent a "healthy" state; Category 2 indicates "gingivitis"; and Categories 3, 4 and 5 suggest "periodontitis". More specifically, Category 3 is thought to be representative of an acute burst of periodontitis; Category 4 is considered to be a previously acute periodontitis that has reverted to a quiescent phase; and, Category 5 is equivalent to a more aggressive periodontitis in either an acute or 
quiescent phase (see photos of the grades in Kerr, 1988, p 70, 72). By using this method, it is possible to record periodontal disease frequency more precisely in past populations and make direct comparisons with epidemiological studies on modern populations. Since at the present time, Kerr's scheme is the most practical method for recording periodontal disease, it is adopted in the present study.

All septa were examined under standardized lighting conditions by careful visual inspection, with the aid of a low-power microscope. When possible, teeth were removed from the alveolus for better evaluation.

Prior to commencement of the main study, several calibration exercises were carried out to ensure that diagnostic criteria were precisely defined and a high level of reproducibility achieved. Data were collected by one observer (SW). Every two weeks, checks for intraexaminer variability were made by repetition of the first individual recording made during that time period. In all, 22 repeats were involved in this intra-observer assessment. The kappa statistics on intra-examiner consistency in the diagnosis of periodontal disease was 0.95 .

\section{RESULTS}

\section{Missing teeth}

The percentages of teeth present, ante-mortem tooth losses, post-mortem tooth losses or fractures, and those with eruption related problems (with sides pooled) by age group are provided in Table S-1.

In all, 19,188 sockets were analysed. The tooth and sockets could be observed (i.e. wear could be recorded) in 9,562 (49.8\%) cases, the socket was visible and recordable but not the tooth (due to post-mortem losses or fractures) in 2,314 (12.1\%) cases, and the tooth was lost ante-mortem in $7,131(37.2 \%)$ cases. 
The number of teeth present decreased with age, particularly in the posterior region, as ante-mortem tooth loss (AMTL) increased. In fact, AMTL increased steadily from $4.6 \%$ in the $20-29$ yr group to $73.2 \%$ in the $70-79$ yr group. Loss of molars was especially marked from 60 years of age onwards. In the oldest age group, the great majority of cheek teeth were missing. Canines were the least frequently missing teeth as age progressed.

Post-mortem tooth loss was higher between 20 and 49 years-of age whereas tooth damage was broadly similar in all age groups. Molars were lost post-mortem less often than incisors or canines. In general, premolars exhibited intermediate levels of both types of tooth loss.

\section{Dental wear}

Figures 1 and 2 show how occlusal wear varies with age across the mouth, in males and females, respectively (for more details see Tables S-2 and S-3, which show the frequency of each occlusal attrition grade of the Smith (1984) system by tooth type and age group among males and females, respectively). Overall, this sample was characterized by relatively slight occlusal attrition levels: $49.0 \%$ of the surfaces were recorded with grade 2 . Wear grades less than 4 were the most common levels in young adults, declining with age, particularly from the age of 50 years in males and 60 years in females onwards. Wear grade 8 was extremely rare in all age groups and was not found in any individual before the age-group of 40-49 years.

Overall, anterior teeth were more severely worn than posterior teeth.

With respect to approximal attrition, $94.4 \%$ of the surfaces were recorded with grade 1 of the Hillson (2001) method, which corresponds to approximal attrition facet confined to the enamel.

\section{Periodontal status}


Table 2 indicates the number of individuals in each age-group and sex, the number of interspaces examined, the number of damaged septal areas that were un-recordable (Category 0 ), and the number of septal areas designated to Categories 1-5.

In all, 17,997 interdental septal areas were analyzed. The percentage of damaged septal areas (Category 0) was $47.8 \%(8,597 / 17,997)$, meaning that 9,400 septal areas were recorded. The main reason was ante-mortem tooth loss, particularly of the molar teeth. It should be kept in mind that the loss of one tooth ante-mortem accounted for the loss of two recordable septal areas. Besides, post-mortem damage of the delicate alveolar bone, particularly in the incisor region, also accounted, although in a lesser extent, to the reduction of the number of recordable septal areas.

Table 3 records the number of individuals with at least 15 recordable septal areas and shows the number and percentage of individuals with healthy septa (Category 1), gingivitis (Category 2), periodontitis (Categories 3, 4 and 5 pooled together), those with minimal destructive lesions (i.e. 1-2 sites as Categories 3, 4 or 5), and those with extensive destructive lesions (i.e. more than $50 \%$ of septa as Categories 3, 4 or 5). No individual had all septal areas healthy. Twenty five percent of the men and $27.5 \%$ of the women were scored with only gingivitis. Most individuals in the present sample were scored with periodontitis, more specifically $74.9 \%$ of the men and $72.5 \%$ of the women. However, only $6.0 \%$ of males and $3.8 \%$ of females already had extensive destructive lesions. More females (33.8\%) than males (26.2\%) had only minimal destructive lesions.

Among individuals between 20 and 29 years-of-age, about $44 \%$ of the men had septal areas scored as having gingivitis and although 56\% presented sites scored with periodontitis, no male had extensive destructive lesions. After about 30 years-of-age the number of males with gingivitis dropped significantly while the percentage of men with periodontitis rose, but again no individual was recorded as having extensive destructive lesions. 
With respect to females, before the age of 30 years, $42 \%$ had septal areas scored as having gingivitis and $58 \%$ had sites with periodontitis. After 30 years-of-age the percentage of females presenting gingivitis fell progressively as the proportion with periodontitis rose. No females over 70 years-of-age had extensive destructive lesions. Instead, $71 \%$ had only minimal extensive lesions.

Since periodontal disease does not consistently occur on every tooth surface of all the teeth within a dentition, Table 4 shows the type of periodontal involvement with respect to sites (not individuals). Table 4 presents the number and percentage of categories 1 to 5 in the six age groups of each sex. Categories 3,4 and 5 were also grouped as one entity which corresponds to more destructive changes.

The healthy state was recorded in $26 \%$ of all analyzed sites. In the younger age group, about $39 \%$ of male sites and $43 \%$ of female areas were scored as healthy, whereas in the older individuals only $14 \%$ of the male septa and $16 \%$ of the female sites were healthy.

Gingivitis was most common in all age groups and both sexes, affecting $60 \%$ of the 9,400 recordable sites. In males, septal areas with gingivitis increased from 53\% in the youngest age group to $76 \%$ in the oldest, whereas in females this rise was from $50 \%$ to $69 \%$.

For all age groups and both sexes, acute bursts of periodontitis were the most common conditions, attributed to $10 \%$ of all recordable sites. More aggressive periodontitis was rare, numbering only $2 \%$ of septal areas. When men between the ages of 50 and 59 years (the most affected by periodontal disease) were considered, approximately $17 \%$ of the septal areas were graded as having acute bursts of periodontitis, $4 \%$ were scored as quiescent phase of periodontitis and 5\% were attributed to more aggressive periodontitis. By contrast, when women between the ages of 70 and 79 years (the most affected by periodontal disease) were considered, about $22 \%$ of the sites were graded as acute bursts of periodontitis, $3 \%$ as 
quiescent phases of periodontitis and $1 \%$ as more aggressive periodontitis. Overall, about 70$80 \%$ of the sites with periodontitis would appear to have been active at the time of death.

More destructive changes were recorded in $14.2 \%$ of all analysed areas. In males, septal areas scored with more destructive changes increased slowly from $8 \%$ in the youngest group to $26 \%$ in the $50-59$ year-old group. Thereafter, the frequency slowly decreased to around $11 \%$ in the oldest group. In women, sites scored with more destructive changes also increased slowly, but this time until the 60-69 year-old group, where $27 \%$ of the sites were scored this way. In the oldest females, $15 \%$ of the septa were scored with more destructive changes.

Highly significant differences were found between the percentages of sites scored healthy, with gingivitis and with more destructive lesions in the different age groups, both among males $\left(\chi^{2}=357.392\right.$, d.f. $\left.=10, p=0.000\right)$ and females $\left(\chi^{2}=314.454\right.$, d.f. $\left.=10, p=0.000\right)$.

Men had fewer areas scored as healthy (24.1\%) than women $(27.5 \%)$ and more sites scored as having gingivitis $(61.1 \%)$ and more destructive lesions $(14.7 \%)$ than the opposite sex (58.9\% and $13.6 \%$, respectively). These differences between men and women were statistically significant $\left(\chi^{2}=14.378\right.$, d.f. $\left.=2, p=0.001\right)$.

Table 5 records the distribution of the five categories of periodontal health and disease in the maxilla and mandible according to sex. In both sexes, there was a statistically significant trend towards more maxillary than mandibular lesions (men: $\chi^{2}=11.525$, d.f. $=2, p=0.003$; women: $\chi^{2}=37.127$, d.f. $\left.=2, p=0,000\right)$. By contrast, within jaws the distribution of lesions of the right and left side of the arch is similar.

Figures 3 and 4 record the percentage of periodontitis episodes by septal area in each age group, in males and females, respectively. It is worthwhile to note that, in both sexes, anterior lower septal areas were more frequently susceptible to periodontal breakdown than the upper interspaces. In males, the most susceptible site to periodontal breakdown was the maxillary second premolar/first molar septal area with $32 \%$ of areas showing periodontitis lesions. The 
least affected areas were the maxillary central/lateral incisors septal areas (4\%). In women, the maxillary first/second molar septal area was the most susceptible site to periodontitis (33\%). The least affected area was the maxillary central incisors inter-space (3\%).

No episodes of periodontitis were recorded in the maxillary inter-incisor septal areas in the younger men (20-29 years). Generally, each maxillary and mandibular septal area showed an increased frequency of periodontitis with age, until the 50-59 year-old group. Between the ages of 60 and 69 years the number of involved septal areas fell, increasing again in the oldest age group, particularly at the maxillary posterior region. The enormous susceptibility of the inter-molar and premolar/molar septal areas is conspicuous in all male age groups. In the oldest males, all recordable upper second/third molars showed destructive changes attributable to periodontitis.

In opposition to men, even in the youngest women, all septal areas were already affected by periodontitis. The least prone area to periodontal destruction was the lateral incisor/canine (only 1\%). As in men, each septal area showed an increased frequency of periodontal breakdown with age, until the 50-59 yr group. In this age group, the upper first/second molar and second premolar/first molar septal areas were the most susceptible to periodontitis, with $54 \%$ and $50 \%$ of areas presenting lesions, respectively. The least prone area for destruction was the lower central/lateral incisor. A decline in the number of involved septal areas was also observed between the ages of 60 and 69 years. In the oldest women, the maxillary second/third molar septal area presented the higher percentage of periodontitis lesions of all age groups $(67 \%)$.

Because periodontal disease declines with age, it was decided to compare these results with AMTL data to investigate if there was any relationship between both conditions. Figures 5 and 6 compare the pattern of AMTL across the mouth with that of periodontal disease in each age group, in males and females, respectively. Not surprisingly, for both sexes, as 
AMTL increases periodontitis prevalence declines, especially in the posterior region of the mouth.

\section{DISCUSSION}

Periodontal disease is frequently analysed as part of bioarchaeological and paleopathologial investigations of the skeletal remains of past populations (DeWitte and Bekvalac, 2010). Many anthropologists are interested in periodontal disease per se and how it might reflect more general levels of health. Epidemiological studies of living people have identified a strong pattern of susceptibility for different teeth and sites within the mouth (Ånerud et al., 1983; Baelum et al., 1988). These studies also identify sex differences in periodontitis prevalence, usually with higher periodontitis rates in men, as well as a strong progression with age (Baelum et al., 1988). Despite these findings, archaeological studies frequently fail to consider factors such as age-at-death and sex when reporting periodontitis in past populations. In this context, the focus of this article is the comparison of periodontal data derived from the Coimbra osteological collections with statistics compiled from epidemiological studies to determine if factors such as age-at-death, sex and tooth type are essential or not to account for in future archaeological studies of periodontitis. Such comparisons permit the following questions to be addressed: 1) Is it possible to identify a pattern of susceptibility for different teeth and sites within the mouth similar to that found by epidemiological studies?; 2) Is there a progression of periodontal disease with age as that found in modern epidemiological studies?; 3) Are there differences between males and females in the age-related progression of periodontal disease and do these vary between different age groups?

Considering the aims of this study, it was necessary to choose adequate clinical studies of periodontitis in adults for comparative purposes (Marshall-Day et al., 1955; Sheiham, 1969; 
Löe et al., 1978, 1986; Ånerud et al., 1983; Pilot et al., 1986; Baelum et al., 1986, 1988). It would be very interesting to compare the figures presented here with periodontal disease distribution in modern Portugal. Unfortunately, this will have to wait until there are Portuguese epidemiological studies that follow periodontal disease throughout life.

Overall, the frequency of periodontitis within the Coimbra collections is $73.8 \%$. In order to try to understand this relatively high frequency, the aetiological factors of periodontitis must be considered. Some studies support the view that periodontitis is more related to age, tooth wear and local immunological factors and has no correlation with carbohydrate-rich diets (Gaengler, 1995). On the contrary, periodontitis may be associated with high-protein/fat diets (Costa, 1982). Other studies suggest that hard food decreases and soft diet increases the incidence of periodontitis (Shaw, 1962).

The daily diet consumed in central Portugal at the beginning of the twentieth century was very simple and relatively soft, consisting of bread made of maize, green and dry vegetables eaten as soups and broths accompanied by potatoes (Roque, 1982). Additionally, a small (but not daily) intake of fish (usually sardine and salted codfish), bacon and olive oil could supplement the overall diet (Bocquet-Appel and Morais, 1987). Accordingly, the Coimbra's group of dentitions was characterized by relatively slight occlusal and approximal attrition levels. In opposition to most archaeological groups, there was no clear gradient between the molars. This may be explained by very slow wear rates. Despite the relatively slight wear levels, anterior teeth were more severely worn than posterior teeth. Consequently, the previous idea that these dentitions were not subjected to the very rapid wear, which characterizes most archaeological collections that antedate the early years of the $19^{\text {th }}$ century, was corroborated in this research. Therefore, it is perhaps not surprising to find relatively high frequencies of periodontitis in the Coimbra sample given such a soft, non abrasive diet and 
considering that oral hygiene and dental care in $19^{\text {th }}-20^{\text {th }}$ centuries Portugal were rudimentary at best (Boléo, 1965; Capelas and Pereira, 1976).

Regarding epidemiological studies, there is a considerable variability between different populations. For instances, Pilot et al. (1986) present the results of 28 CPITN (Community Periodontal Index of Treatment Needs) surveys in 24 countries for individuals between 35-44 years-of-age. In their study, the percentage of persons who have as highest score shallow pockets or deep pockets ranges between $4 \%$ for Zimbawe and 100\% for Burkina Faso. For Portugal, the percentage presented in this overview is $46 \%$. According to Pilot et al. (1986), however, evaluation and discussion of these data calls for caution because not only were the surveys carried out by different investigators under varying field conditions, but the sampling methods also differed considerably. Here, the need of a universally accepted assessment method for the periodontal status of living patients stands out.

In the Coimbra collections, despite bilateral symmetry within jaws, there was a statistically significant trend towards more maxillary than mandibular periodontal lesions. Men were more susceptible to periodontal disease than women. Not only did men have less healthy areas than women, but they also showed more sites with gingivitis and periodontitis than their female counterparts. In males, the most susceptible site to periodontal breakdown was the maxillary second premolar/first molar septal area, and the least affected areas were the maxillary central/lateral incisors septal areas. In women, the maxillary first/second molar septal area was the most susceptible site to periodontitis, and the least affected area was the maxillary central incisors inter-space.

A strong pattern of susceptibility for different teeth and sites within the mouth has been also identified by several studies of living people conducted throughout the world on a variety of populations (Ånerud et al., 1983; Baelum et al., 1988). Besides, many of these studies identify sex differences in periodontitis prevalence, usually with higher periodontitis rates in 
men (Baelum et al., 1988), although some studies do not distinguish between men and women.

In the present study, no individual was recorded as having an entirely healthy periodontium. Gingivitis was widespread in the younger age groups. Destructive periodontitis was observed early in adulthood, rising steadily with age. Besides, there were highly significant differences between the percentages of sites scored healthy, with gingivitis and with more destructive lesions in the different age groups, both in males and females.

Although these results are in general agreement with previous epidemiological studies of the living (Marshall-Day et al., 1955; Sheiham, 1969; Löe et al., 1978, 1986) supporting the view that the prevalence of periodontitis increases with age, it was necessary to find comparative studies of adults of all ages, divided into age groups, and reporting periodontal disease separately for the two sexes and different teeth, in order to address the more specific questions posed above. Relatively few studies fit these criteria.

Baelum et al. (1988) studied a full range of adult ages in a sample of 1,131 living people examined during 1985/6 in rural Kenya. They were divided into five age groups (ten years in each), starting with 15 years and ending with 65 years. This makes a good comparison with the present study because the data were plotted separately for different teeth and different sexes and ages. In addition, as with the people in the Coimbra collection, the Kenyan patients lived in an area with limited access to dental care. In Baelum et al.'s study, each person was examined for mobility of each tooth present and for dental plaque, calculus, gingival bleeding, loss of periodontal attachment and pocket depth on the mesial, buccal, distal and lingual surfaces of the teeth. Information on the pattern of ante mortem tooth loss in this population is given in separate papers (Manji et al., 1988, 1989).

In Baelum et al.'s (1988) study, Kenyan men had a significantly higher proportion of surfaces with loss of attachment than women. The extent of periodontal breakdown varied 
within the mouth so that certain teeth and sites showed more advanced loss of attachment than others. Irrespective of age and type of surface, first molars were consistently the teeth most affected by loss of attachment. This appears to be very much in keeping with the findings of the Coimbra survey, where the most susceptible sites were the maxillary second premolar/first molar area for men and the first/second molar area for women.

There was also a clear trend with age in Kenya. Loss of attachment affected 5-10\% of the surfaces in the 15-24 year olds and $75-85 \%$ of the surfaces in the oldest age group. Although the increase in the frequency of destructive periodontitis with age resembles that observed in the Coimbra study, it differs in the proportion of affected sites in the older age groups, which was found to be much higher than that seen in Coimbra. This difference may be a biased result, explained by the severe ante-mortem loss of the previously affected teeth in the Coimbra population. In fact, in the present study, the proportion of teeth missing ante-mortem at each potential tooth position in the dentition rose much more sharply with age than in the Kenya study (Manji et al., 1988, 1989). As it can be seen in Figures 5 and 6, in age group 5 (60-69 year), approximately $80 \%$ of Coimbra molars were missing ante-mortem, whereas some $40 \%$ of the Kenya molars in the 55-64 year age group were missing. Moreover, in the Kenyans' oldest age group, more than $50 \%$ of the individuals had at least 26 remaining teeth and $90 \%$ had at least 16 remaining teeth. For Coimbra, as the surviving teeth decreased in number, the proportion of sites affected by periodontal breakdown fell more sharply in the older age groups than was the case for Kenya, although the effect is emphasized by the inclusion of an older 70-79 year age group 6 for Coimbra. On the other hand, the Coimbra study is much more in accordance with the overview of CPITN (Community Periodontal Index of Treatment Needs) data in the WHO Global Oral Data Bank (Pilot et al., 1986), which indicated that the prevalence of periodontitis was of a "notable magnitude" but the progress of the disease state was slow. As already noted by other authors (Oztunc et al., 
2006), although age is associated with an increasing prevalence of periodontal disease, it is still unknown whether periodontal tissues become more susceptible to breakdown with increasing age, or whether the breakdown is related to an increasing exposure to risk factors rather than age per se.

Of particular interest in Baelum et al.'s finding that a small, but increasing minority of individuals was responsible for the major part of the loss of attachments observed. They also reported that it was possible to have massive microbial accumulation along the marginal periodontium for a period of 20 years (6 to 25 years) without there being any significant sign of irreversible breakdown except at a few sites in a minority of subjects. In a previous study of an adult Tanzanian population of limited size, Baelum et al. (1986) had already shown that a relatively minor fraction of the population accounted for the majority of periodontal breakdown despite very poor oral hygiene in all individuals. Similarly, Löe et al. $(1978,1986)$ in their study on Sri Lankan male laborers, based on interproximal loss of attachment, were able to identify three groups of individuals, a small group (approximately 8\%) with rapidly progressive disease, a large group (around $81 \%$ ) with moderately progressive disease, and another small group (approximately 11\%) with virtually no disease progression beyond gingivitis. A similar pattern has been found in some archaeological studies. In the Mycenean (1450-1150 BC) population of Aghia Triada (Greece), for example, Tsilivakos et al. (2002) found that a small subset of the analyzed sample, approximately $10 \%$, demonstrated a profile of generalized destructive periodontitis, and that another larger subset $(25 \%)$ seemed to be resistant to the disease. A comparable ratio was obtained by Kingsmill (1991) for the $18^{\text {th }}$ century Spitalfields population. In the Coimbra study, the figures presented in Table 3 suggest a comparable pattern of disease distribution. For instance, in the 50 to 59 year age group, where more than $90 \%$ of the individuals were affected by periodontitis, four $(8.5 \%)$ individuals did not show any signs of the disease (no disease progression) and six (12.8\%) 
individuals had at least half of their septa with destructive periodontitis lesions. One woman in this age group had 18 out of 21 recordable septa with destructive periodontitis lesions, suggesting a particularly high susceptibility to the disease.

The present study distinguished between septal interspaces that were active and septal areas that were quiescent at the time of death, and suggested that around 70-80\% may have been active. However, this figure should be accepted with caution as it might possibly reflect the relationship between poor health and periodontal disease, as a death assemblage is likely to contain individuals with a poorer record of health than the living populations as a whole (Wood et al., 1992).

It is now possible to address the research questions posed above. There is a considerable variation in reported frequencies of periodontitis in clinical reports, which might result from variation in methods for identifying the pathology, differences in the age composition of the samples examined, variation in oral hygiene and/or diet, or some other factors (Kerr, 1991; Oztunc et al., 2006; DeWitte and Bekvalac, 2010). Future work might fruitfully establish a universal accepted assessment method for the periodontal status of both archaeological material and living patients.

Regarding epidemiological studies, the results of the Coimbra study are consistent with the most appropriate study available for periodontal disease in living adults, conducted some 60-80 years after the Coimbra people died, with respect to the pattern of periodontal disease around the dentition, sexual differences in periodontitis frequencies, and age-related progression of this disease. At the present time, however, it is unknown whether periodontal tissues become more susceptible to breakdown with increasing age, or whether the breakdown is related to an increasing exposure to risk factors rather than age per se. Nevertheless, these results make clear the importance of considering sex, age, dental wear, ante-mortem tooth loss, and oral distribution of periodontitis in future archaeological studies. Only equally 
detailed archaeological studies will allow proper comparisons, namely to test whether periodontal disease in populations experiencing high wear rates are distinctively different from the "modern" pattern presented here.

\section{ACKNOWLEDGMENTS}

The authors would like to thank the Museum of Anthropology of the University of Coimbra for permission to study the identified osteological collections. The authors also acknowledge the Editor-in-Chief of the journal, the Associate Editor and the anonymous reviewers whose valuable comments and suggestions allowed us to improve the manuscript.

\section{LITERATURE CITED}

American Academy of Periodontology. 2003. Diagnosis of periodontal diseases (position paper). J Periodontol 74: 1237-1247.

Ånerud KE, Robertson PB, Löe H, Ånerud Å, Boysen H, Patters MR. 1983. Periodontal disease in three young adult populations. J Periodontal Res 18: 655-668.

Apsey DJ, Kaciroti N, Loesche WJ. 2006. The diagnosis of periodontal disease in private practice. J Periodontol 77: 1572-1581. DOI: 10.1902/jop.2006.050449

Baelum V, Fejerskov O, Karring T. 1986. Oral hygiene, gingivitis and periodontal breakdown in adult Tanzanians. J Periodontal Res 21: 221-232.

Baelum V, Fejerskov O, Manji F. 1988. Periodontal diseases in adult Kenyans. J Clin Periodontol 15: 445-452.

Bocquet-Appel J-P, and Morais MHX. 1987. Anthropologie et Histoire. Un essai de reconstrution de la variation biologique de la population portugaise au XIXe siécle. Paris: Fundação Calouste Gulbenkian. 
Boléo JP. 1965. A higiene da boca através dos tempos até à época presente. Separata de Revista Portuguesa de Estomatologia e Cirurgia Maxilofacial nº 3 e 4.

Capelas M, and Pereira A. 1976. As escolas superiores de Medicina Dentária e a assistência odonto-estomatológica em Portugal. Separata de O Médico nº 1305.

Clarke NG, Carey SE, Srikandi W, Hirsch RS, Leppard PI. 1986. Peridontal disease in ancient populations. Am J Phys Anthropol 71: 173-183.

Costa RL. 1982. Periodontal disease in the prehistoric Ipiutak and Tigara remains from Point Hope, Alaska. Am J Phys Anthropol 59: 97-110.

Cunha E, and Wasterlain S. 2007. The Coimbra identified osteological collections. In: Grupe G, Peters J, editors. Skeletal series and their socio-economic context. Documenta Archaeobiologiae, vol. 5. Verlag Marie Leidorf GmbH: Rahden/Westf.; 23-33.

DeWitte SN, Bekvalac J. 2010. Oral health and frailty in the Medieval English cemetery of St Mary Graces. Am J Phys Anthropol 142: 341-354. DOI: 10.1002/ajpa.21228

Gaengler P. 1995. Lehrbuch der konservierenden Zahnheilkunde, Berlin: Ullstein Mosby. Hillson S. 2000. Dental pathology. In: Katzenberg MA, Saunders SR, editors. Biological anthropology of the human skeleton. New York: Alan R. Liss. p 249-286.

Hillson S. 2001. Recording dental caries in archaeological human remains. Int J Osteoarchaeol 11: 249-289.

Hillson S. 2005. Teeth. Cambridge Manuals in Archaeology. $2^{\text {nd }}$ edn. Cambridge: Cambridge University Press.

Kerr NW. 1988. A method of assessing periodontal status in archaeologically derived skeletal material. J Paleopathol 2(2): 67-78.

Kerr NW. 1989. The periodontal status of a Scottish Mediaeval cohort. J Paleopathol 2(3): 119-128. 
Kerr NW. 1991. Prevalence and natural history of periodontal disease in Scotland - the medieval period (900-1600 A.D.). J Periodontal Res 26: 346-354.

Kerr NW. 1998a. Prevalence and natural history of periodontal disease in prehistoric Scots (pre-900 AD). J Periodontal Res 33: 131-137.

Kerr NW. 1998b. The prevalence and natural history of periodontal disease in Britain from prehistoric to modern times. Br Dent J 185: 527-535.

Kingsmill V. 1991. Chronic periodontitis in an Eighteenth Century population. Br Dent J 170: 118-120.

Lavigne SE, and Molto JE. 1995. System of measurement of the severity of periodontal disease in past populations. Int J Osteoarchaeol 5: 265-273.

Löe H, Anerud A, Boysen H, Smith M. 1978. The natural history of periodontal disease in man. The rate of periodontal destruction before 40 years of age. J Periodontol 49: 607620.

Löe H, Anerud A, Boysen H, Morrison E. 1986. Natural history of periodontal disease in man. Rapid, moderate and no loss of attachment in Sri Lanken labourers 14 to 46 years of age. J Clin Periodontol 13: 431-445.

Manji F, Baelum V, Fejerskov O. 1988. Tooth mortality in an adult rural population in Kenya. J Dent Res 67: 496-500.

Manji F, Fejerskov O, and Baelum V. 1989. Pattern of dental caries in an adult rural population. Caries Res 23: 55-62.

Marshall-Day CD, Stephens RG, Quigley LF. 1955. Periodontal disease: prevalence and incidence. J Periodont 26: 158-203.

Oztunc H, Yoldas O, Nalbantoglu E. 2006. The periodontal disease status of the historical population of Assos. Int J Osteoarchaeol 16: 76-81. DOI: 10.1002/oa.805 
Page RC, Eke PI. 2007. Case definitions for use in population-based surveillance of periodontitis. J Periodontol 78: 1387-1399. DOI: 10.1902/jop.2007.060264

Pilot T, Barmes DE, Leclercq MH, McCombie BJ, Sardo IJ. 1986. Periodontal conditions in adults 35-44 years of age: an overview of CPITN data in the WHO Global Oral Data Bank. Community Dent Oral Epidemiol 14: 310-312.

Roque JL. 1982. Classes populares no Distrito de Coimbra no séc. XIX (1830-1870). Contributo para o seu estudo. Ph.D. dissertation, University of Coimbra.

Shaw JH. 1962. The relation of nutrition to periodontal disease. J Dent Res 41: 264.

Sheiham A. 1969. The prevalence and severity of periodontal disease in British populations: dental surveys of employed populations in Great Britain. Brit Dent J 126: 115-122.

Smith BH. 1984. Patterns of molar wear in hunter-gatherers and agriculturalists. Am J Phys Anthropol 63: 39-56.

Soames JV, and Southam JC. 2005. Oral pathology. Oxford: Oxford University Press.

Tsilivakos MG, Manolis SK, Vikatou O, and Papagrigorakis MJ. 2002. Periodontal disease in the Mycenean (1450-1150 BC) population of Aghia Triada, W. Peloponnese, Greece. International Journal of Anthropology 17: 91-100.

Waldron T. 1994. Counting the dead: the epidemiology of skeletal populations. Chichester: John Wiley \& Sons.

Williams DM, Hughes FJ, Odell EW, and Farthing PM. 1992. Pathology of periodontal disease. Oxford: Oxford University Press.

Wood JW, Milner GR, Harpending HC, Weiss KM. 1992. The osteological paradox: problems of inferring health from skeletal samples. Current Anthropology 33: 343-370. 
Fig. 1. Occlusal wear average and standard deviation rates for each tooth class (molars, premolars, canines, and incisors) and age group, in males.

Fig.2. Occlusal wear average and standard deviation rates for each tooth class (molars, premolars, canines, and incisors) and age group, in females.

Fig. 3. Percentages of periodontitis episodes (Categories 3, 4 and 5) by septal area in each age group, in males. Upper septa are above the line and lower below.

Fig. 4. Percentages of periodontitis episodes (Categories 3, 4 and 5) by septal area in each age group, in females. Upper septa are above the line and lower below.

Fig. 5. Periodontitis and ante-mortem tooth loss frequency rates for each tooth class (molars, premolars, canines, and incisors) and age group, in males. Upper dentition is above the line and lower below.

Fig. 6. Periodontitis and ante-mortem tooth loss frequency rates for each tooth class (molars, premolars, canines, and incisors) and age group, in females. Upper dentition is above the line and lower below. 
TABLE 1. Description of the six category assessment of the interdental septal areas suggested by Kerr (1988: 69-71).

\begin{tabular}{|c|c|}
\hline Category & Architectural and textural variations of the interdental septum \\
\hline 3 & $\begin{array}{l}\text { Septal form showing a breakdown of contour with bone loss in the form of a shallow depression extending across the interspace } \\
\text { from the buccal to lingual aspect, or as one or two smaller discrete areas of bone destruction, the essential distinguishing features } \\
\text { being a sharp and ragged texture to bone defect. }\end{array}$ \\
\hline 4 & $\begin{array}{l}\text { Septal form showing breakdown of contour with bone loss similar to that seen in category } 3 \text {, the essential difference being the bone } \\
\text { surface, instead of being ragged in appearance, showed a porous or smooth honeycomb effect with all defects rounded. }\end{array}$ \\
\hline 5 & $\begin{array}{l}\text { Presence of a deep infra-bony defect with sides sloping at } 45 \text { degrees or more and with a depth of } 3 \mathrm{~mm} \text { or more. The defect is more } \\
\text { likely to be mesio-distally but may be bucco-lingually inclined. The surface may be sharp and ragged or smooth and honeycombed. }\end{array}$ \\
\hline
\end{tabular}


TABLE 2. Number of individuals and number of interseptal areas available for assessment.

\begin{tabular}{|c|c|c|c|c|c|c|c|}
\hline & \multirow[t]{2}{*}{ Age group } & \multirow{2}{*}{$\begin{array}{c}\text { Individuals } \\
\mathrm{N}\end{array}$} & \multirow{2}{*}{$\begin{array}{c}\text { Septal areas available } \\
\mathrm{N}\end{array}$} & \multicolumn{2}{|c|}{ Septal areas category 0} & \multicolumn{2}{|c|}{ Septal areas categories 1 to 5} \\
\hline & & & & $\mathrm{N}$ & $\%$ & $\mathrm{~N}$ & $\%$ \\
\hline \multirow[t]{6}{*}{ Males } & 1 & 50 & 1500 & 209 & 13.9 & 1291 & 86.2 \\
\hline & 2 & 50 & 1500 & 332 & 22.1 & 1168 & 77.9 \\
\hline & 3 & 50 & 1500 & 517 & 34.5 & 983 & 65.5 \\
\hline & 4 & 50 & 1500 & 711 & 47.4 & 789 & 52.6 \\
\hline & 5 & 50 & 1498 & 986 & 65.8 & 512 & 34.2 \\
\hline & 6 & 50 & 1500 & 1263 & 84.2 & 237 & 15.8 \\
\hline \multirow[t]{6}{*}{ Females } & 1 & 50 & 1500 & 216 & 14.4 & 1284 & 85.6 \\
\hline & 2 & 50 & 1500 & 409 & 27.3 & 1091 & 72.7 \\
\hline & 3 & 50 & 1499 & 578 & 38.6 & 921 & 61.4 \\
\hline & 4 & 50 & 1500 & 952 & 63.5 & 548 & 36.5 \\
\hline & 5 & 50 & 1500 & 1221 & 81.4 & 279 & 18.6 \\
\hline & 6 & 50 & 1500 & 1203 & 80.2 & 297 & 19.8 \\
\hline Total & & 600 & 17997 & 8597 & 47.8 & 9400 & 52.2 \\
\hline
\end{tabular}


TABLE 3. Periodontal health status by sex, by age and by categories.

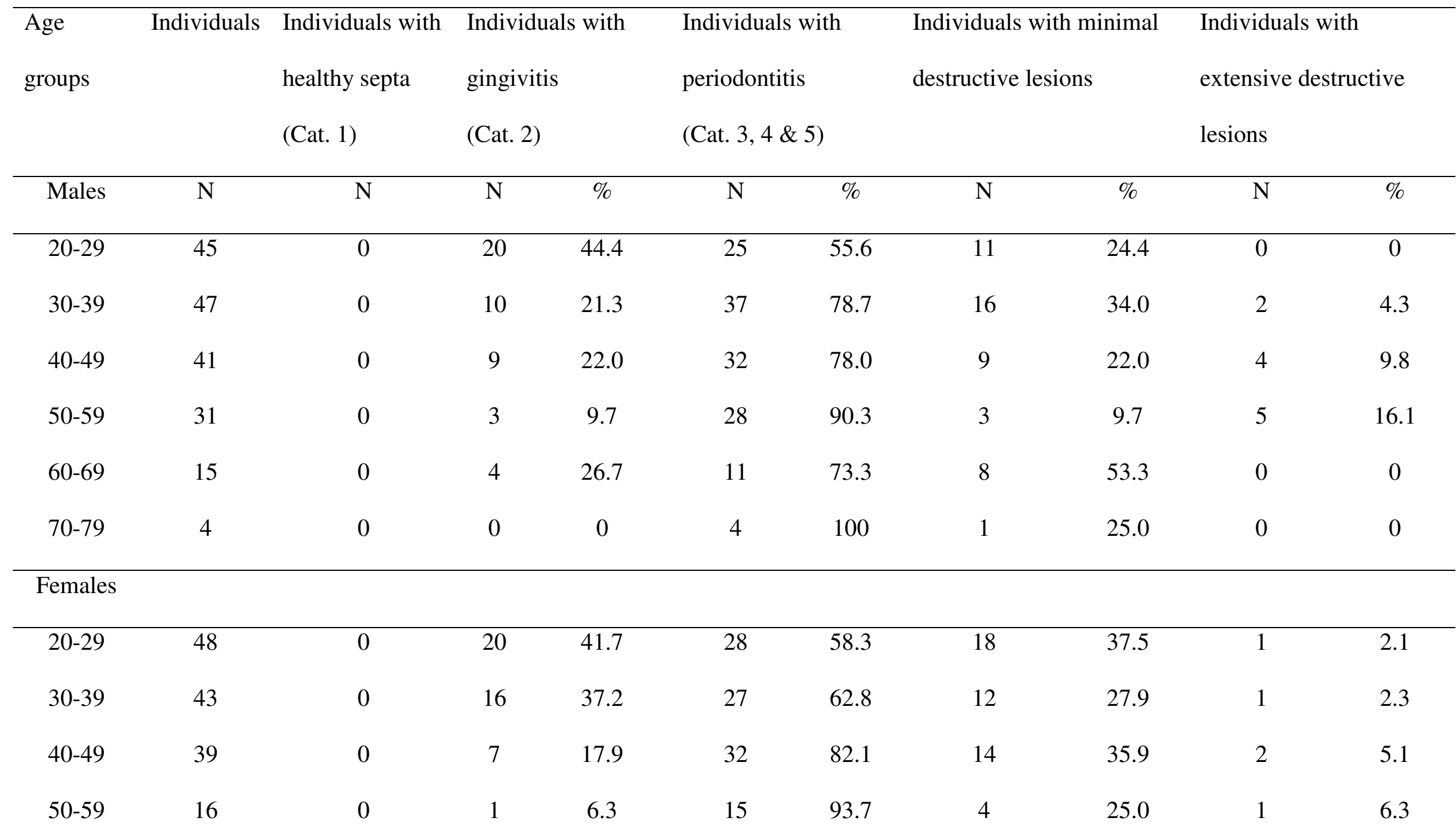


Page 33 of 42

American Journal of Physical Anthropology

\begin{tabular}{ccccccccccc}
$60-69$ & 7 & 0 & 0 & 0 & 7 & 100 & 1 & 14.3 & 1 & \\
$70-79$ & 7 & 0 & 0 & 0 & 7 & 100 & 5 & 71.4 & 0 \\
\hline Total & 343 & 0 & 90 & 26.2 & 253 & 73.8 & 102 & 29.7 & 17 \\
\hline
\end{tabular}


TABLE 4. Number and percentage of category 1 to 5 sites, by sex and age group.

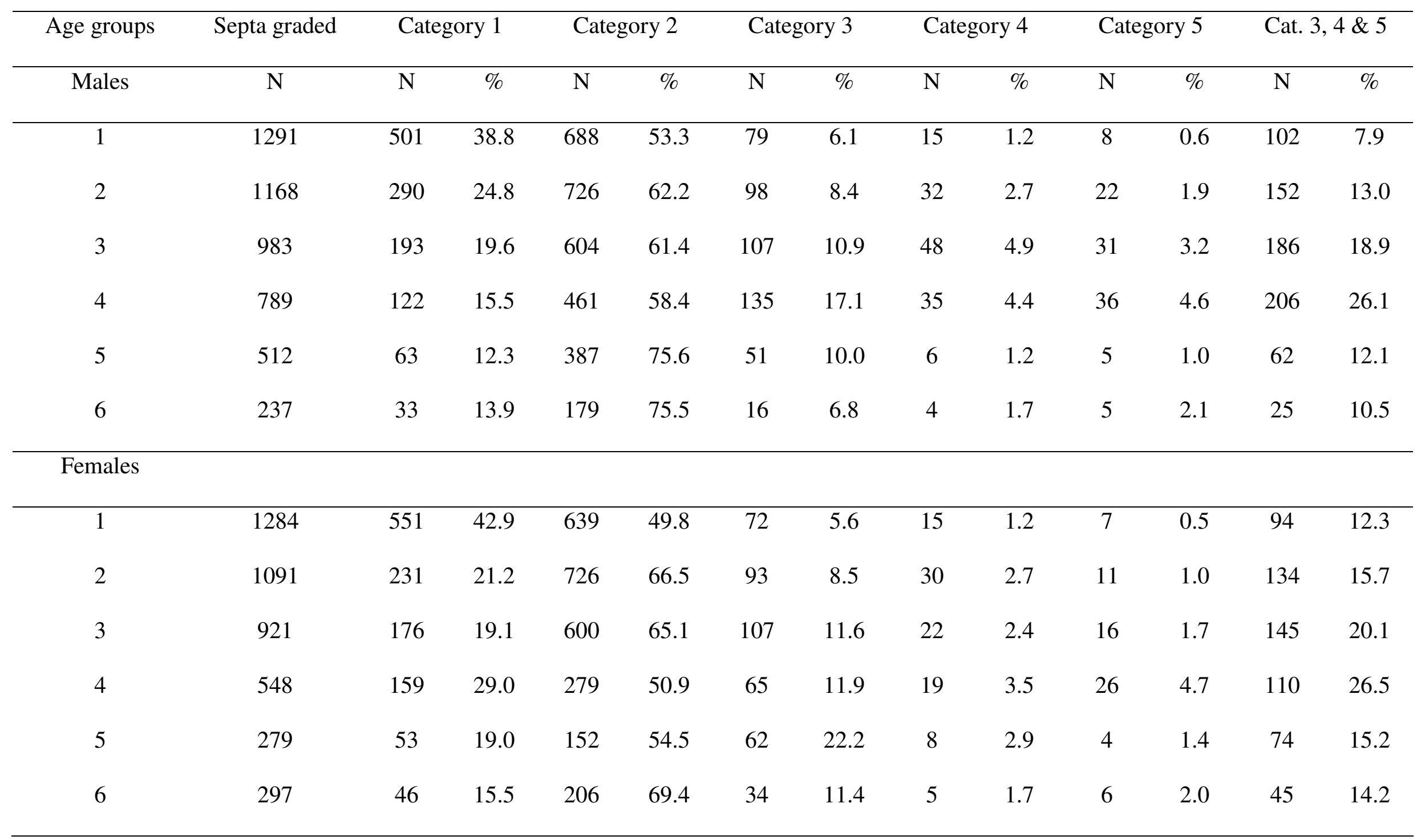




\section{Page 35 of 42}

American Journal of Physical Anthropology

2418

25.7

5647

60.1

919

$9.8 \quad 239$

2.5

177

$1.9 \quad 1335$

14.2 
TABLE 5. Number and percentage of category 1 to 5 sites, by jaw, sex and age group.

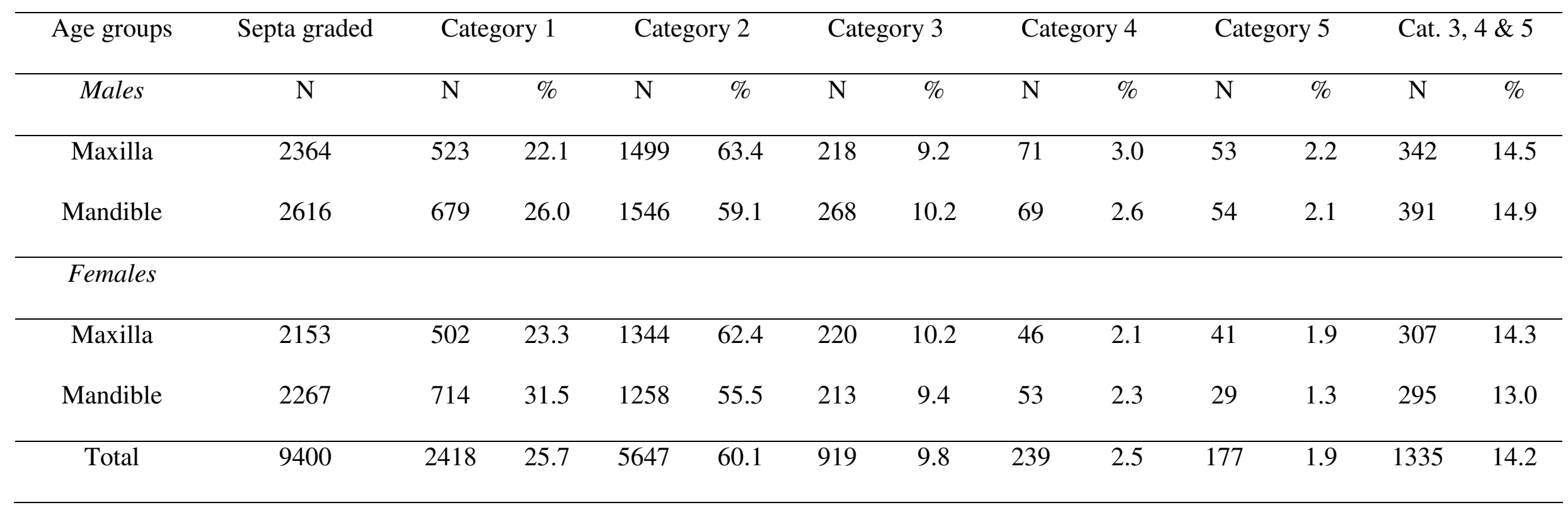




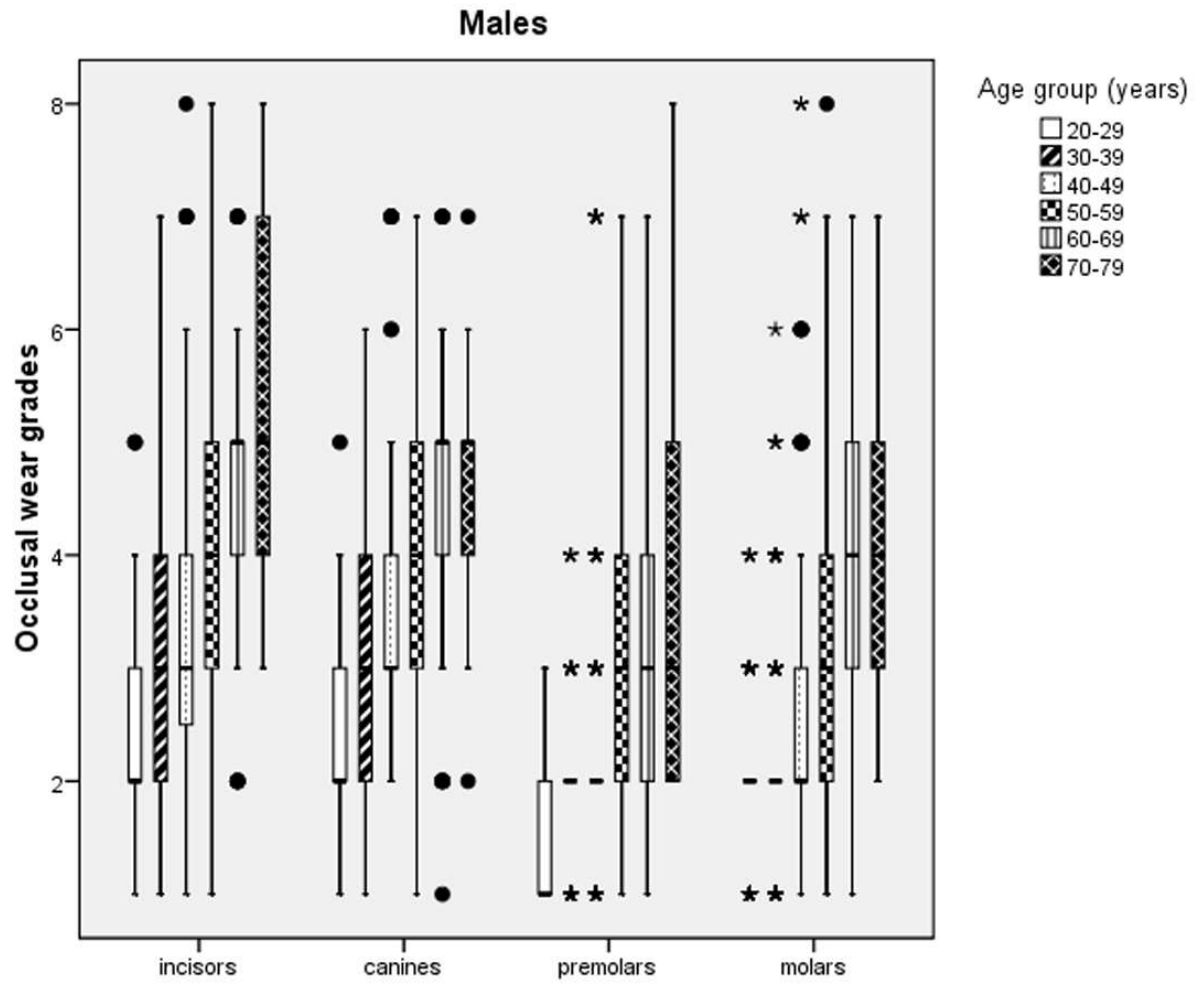

Fig. 1. Occlusal wear average and standard deviation rates for each tooth class (molars, premolars, canines, and incisors) and age group, in males. $49 \times 43 \mathrm{~mm}(600 \times 600 \mathrm{DPI})$ 


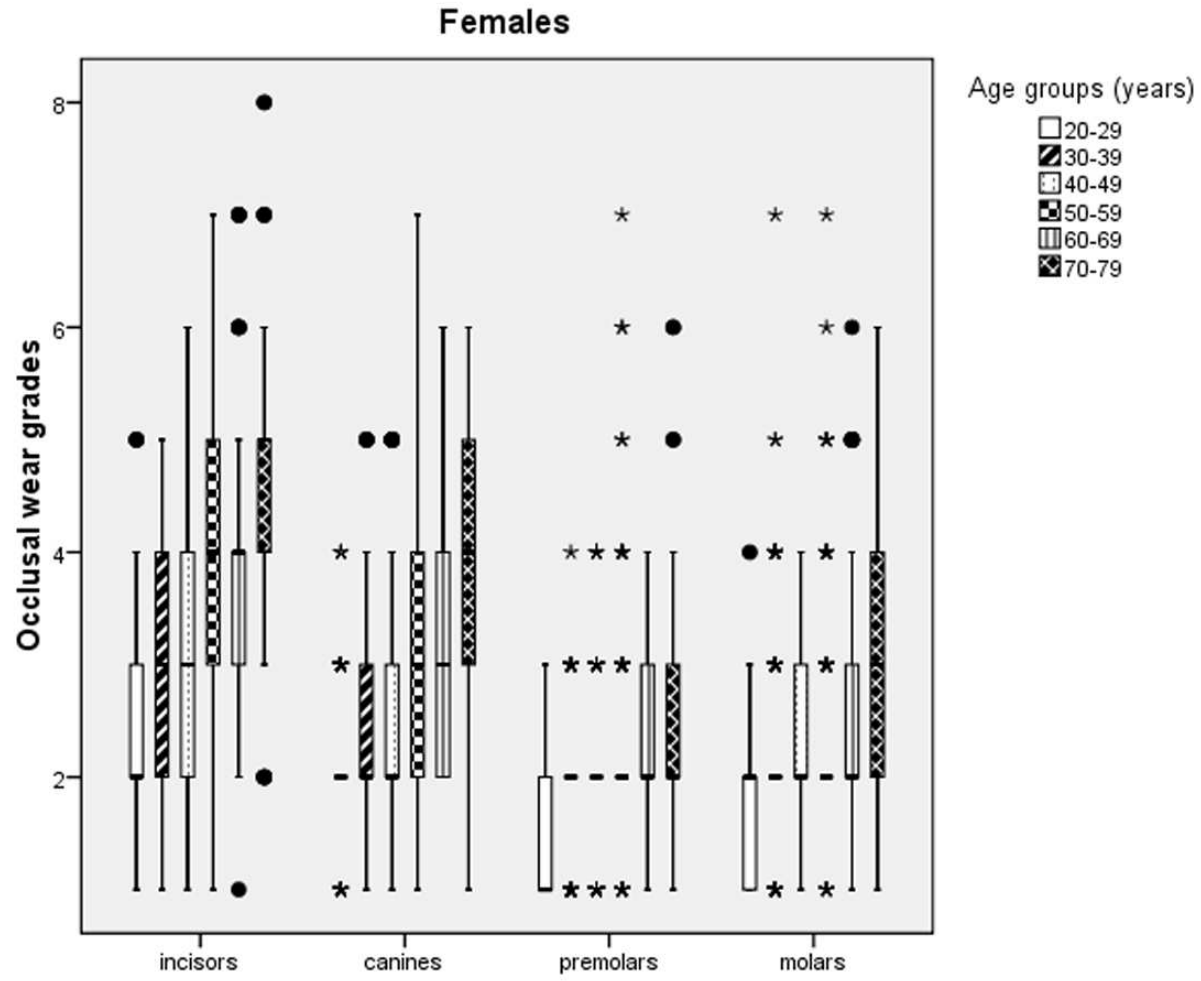

Fig.2. Occlusal wear average and standard deviation rates for each tooth class (molars, premolars, canines, and incisors) and age group, in females. $49 \times 43 \mathrm{~mm}(600 \times 600 \mathrm{DPI})$

40

41

42

43

44

45

46

47

48

49

50

51

52

53

54

55

56

57

58

59

60

John Wiley \& Sons, Inc. 
Fig. 3. Percentages of periodontitis episodes (Categories 3, 4 and 5) by septal area in each age group, in males. Upper septa are above the line and lower below. $97 \times 55 \mathrm{~mm}(600 \times 600$ DPI $)$ 
Fig. 4. Percentages of periodontitis episodes (Categories 3,4 and 5) by septal area in each age group, in females. Upper septa are above the line and lower below. $97 \times 55 \mathrm{~mm}(600 \times 600 \mathrm{DPI})$ 
Fig. 5. Periodontitis and ante-mortem tooth loss frequency rates for each tooth class (molars, premolars, canines, and incisors) and age group, in males. Upper dentition is above the line and lower below.

$80 \times 45 \mathrm{~mm}(600 \times 600$ DPI $)$

John Wiley \& Sons, Inc. 
Fig. 6. Periodontitis and ante-mortem tooth loss frequency rates for each tooth class (molars, premolars, canines, and incisors) and age group, in females. Upper dentition is above the line and lower below.

$80 \times 45 \mathrm{~mm}(600 \times 600 \mathrm{DPI})$

John Wiley \& Sons, Inc. 